\title{
Results of experiments with Chinese pig breeds in France : reproduction and production
}

\author{
C. LEGAULT *, J.C. CARITEZ **, J. GRUAND***, J.P. BIDANEL * \\ I.N.R.A. \\ * Station de Génétique quantitative et appliquée, 78350 Jouy-en-Josas \\ ** Domaine expérimental du Magneraud, 17700 Surgères \\ *:** Station expérimentale de Sélection porcine, 86480 Roullle \\ France
}

The reproduction and production performances of three Chinese breeds - Meishan (MS), Jiaxing (JX) and Jinhua $(\mathrm{JH})$ - and of the offsprings from crossing between Chincse and European breeds - Large White (LW) and French Landrace (FL) - and three boar types used in terminal crossing, were compared.

The reproductive performances were analysed in 557 litters born from 216 sows. According to the variable considered, genotypes were distributed into 2 to 5 groups whose mean performances were significantly different the one from the others. The variable "litter size" could be divided into two groups of which the most prolific one included MS, MS $\times J X, M S \times(L W$ or FL) and $J X \times(L W$ or FL $)$ females. The number of piglets per litter varied between 14.9 to 15.8 at birth, from 12.8 to 13.4 at weaning. The variable "litter weight" could be divided into 3 to 5 groups, the heaviest litters at 21 days being suckled by sows $\mathrm{MS} \times(\mathrm{LW}$ or $\mathrm{FL})$ and $\mathrm{JX} \times(\mathrm{LW}$ or $\mathrm{FL})(67.8$ and $64.5 \mathrm{~kg}$, respectively). During 30 days of lactation, the feed intake of the European sows (LW and FL) exceeded by $42 \mathrm{~kg}$ that of Chinese F1 sows and by $67-86 \mathrm{~kg}$ that of purebred Chinese sows. According to these results $F 1$ females may wean 6 to 9 more piglets per year than European sows.

Using a total of 1070 animals the production performances were compared between “ $1 / 4$ Chinese" and European control - $(\mathrm{LW} \times \mathrm{FL}) \times$ Belgian Landrace - on the one hand, "1/4 Chinese" and "1/8 Chinese" on the other hand.

The age at slaughter $(100 \mathrm{~kg})$ of " $1 / 4 \mathrm{MX}$ " and " $1 / 4 \mathrm{JX}$ " was comparable to that of the European control, on the one hand $(-15$ and +6 days, respectively) and the " $1 / 8$ Chinese $»$, on the other hand $(+2$ and +10 days, respectively). But they exhibited a poorer food conversion ratio $(+0.21$ to $0.39 \mathrm{~kg}$ as compared to the European controls, +0.17 to $+0.19 \mathrm{~kg}$ as compared to " $1 / 8$ Chinese ") and a poorer body composition, "1/4 MS" and " $1 / 4 \mathrm{JX}$ " carcasses contained 4-4.3 p. 100 less lean than the European controls and the " $1 / 8$ Chinese". The meat quality differences observed (pH, soaking time, reflectance) were small and showed a trend in favour of Chinese crossbreds. Marked variations in production performances were observed according to the type of terminal boar used.

The production and reproduction results obtained with $\mathrm{JH}$ crossbreds were lower than those of their MS and JX homologues.

Various strategies aiming at valorizing Chinese breeds (MS and JX) in crossbreeding, are discussed. 